\title{
Management of knowledge employee performance
}

\author{
AN Lu ${ }^{1, a}$ \\ ${ }^{1}$ School of management ,Tianjin polytechnic university, Tianjin 300387, China \\ aanlu2013@yeah.net
}

Keywords: Knowledge employee; Performance; Performance management

\begin{abstract}
In the era of knowledge economy, knowledge employee is increasingly becoming the core of the modern enterprise resources and the performance of knowledge employee determines the enterprise's core competitiveness. This paper studies the meaning and characteristics of knowledge employee, and the analysis based on the traditional concept of performance, from the perspective of the stakeholders define the knowledge-based employee performance, summarized the effect factors of knowledge employee performance, proposed considerations and suggestions to improvement of knowledge employee performance.
\end{abstract}

\section{Introduction}

Human society has entered the era of knowledge economy, people are becoming more deeply felt the importance of knowledge and its impact on a huge role in promoting economic growth. As Drucker has said, the knowledge will replace the natural resources, financial capital, etc., and become the most important resource. Modern manufacturing is gradually transition to a knowledge-intensive, extensive penetration of information technology and the new requirements for the laborers, making a labor who do the traditional, simple and low value-added difficult to become the main force to enhance enterprise competitiveness and promote enterprise modernization. While the number of knowledge employee and the quality is increasingly becoming the focus of attention.

\section{The related research of knowledge employee}

\subsection{The explaining of the knowledge employee}

Knowledge employee" was firstly created by American scholar Peter Drucker, which refers to the "person master and use symbol and concept, who use the knowledge or information for working." Obviously, knowledge employee refers to the man who engaged in manufacture, creation and expansion and application of knowledge activities for the enterprise (or organization) to bring knowledge capital appreciation and take it as a major duty.

\subsection{The characteristics of knowledge employee}

Compared with Non-knowledge employee, knowledge employee has many particularity in many aspects, for example, personal qualities, values, psychological needs and behavior, etc.

1. They have a highly creative and autonomous independence. Creative power is the important features of the knowledge employee. Their work is not the easy and repetitive, but gives the full play to their individual ability to prepare the anything to happen to promo the development of technique in a changeable and uncertain system, and their importance is reflected in the knowledge that they have the ability to be useful innovation. In addition, knowledge workers prefer to have a more independent work environment, they are not only unwilling to chained down to matter, and even intolerable distant superiors remote command, they are more emphasis the self-directed, self-management and control in work.

2. They have the corresponding techniques and higher human capital content. Most knowledge workers received systematic professional education, with higher education and have a certain amount of professional knowledge and skills. Due to higher levels of education, most knowledge workers with high personal qualities, such as the broad vision, strong thirst for knowledge, strong learning ability, extensive knowledge of the level of literacy and other capacities. 
3. They has a strong desire to achieve self-worth, attaches great importance to achievement motivation and mental stimulation. Knowledge employee usually has higher level of demand, with a strong desire to achieve self-worth. They difficult to meet the general work and more interested in challenging creative task, eager to the results of the work, expect from their work get a lot of internal satisfaction. Relatively speaking, money and promotion and other traditional incentives are relegated to secondary status.

\section{Knowledge employee performance and its influencing factors}

\section{1 Traditional Performance and Its Defects}

People focus on performance in a long time, but "What is the performance of" general agreement has not yet been defined, the focus of attention from the different definitions of the performance can be divided into about two kinds [4]:

1. "Results" oriented performance concept. In this viewpoint, it will be equal to the task performance results that the performance was "in a specific period of time, by a specific job function or activity generated output records." The advantage of taking into account the customer's attitude and effort individuals with organizations target combines. However, this economic system built on industry thinking on performance management in the knowledge economy has its obvious shortcomings: The performance evaluation as orientation, ignoring the process, it is unable to improve future performance and provides guidance, moreover it is ignore its own staff can not the control of the impact on performance and not conducive to teamwork and so on.

2. "Capacity" oriented performance concept. In this viewpoint, the staff can be distinguished by their ability to identify the strengths and weaknesses in their work performance, the basic assumption is that qualified employees can bring qualified performance. The advantage of this viewpoint is enough to introduce a thought evaluation of feed forward control, it can indicate employee relative ability through of evaluation before work started and evaluate if employee get the improvement during their work, thereby providing a feedback-based learning mechanism. Of course. This view also has shortcomings: not consider motivation and attitudes impact on employee performance; definition of capacity content and disputed, it is difficult to quantify the assessment and distinguish of ability and easy to cause controversy.

\subsection{Knowledge employee performance}

All three performance concept have their disadvantages according to the traditional performance analysis, all of them cannot be directly used as the definition of employee performance, then how to define the performance of knowledge workers do? As we know, in a knowledge economic era, enterprise provide a high, abundant and personalized service, knowledge employee is the core to increase their competitiveness of corporation during the process, meanwhile knowledge employee shall take the realization of their value as the goal. We can find three main related parts: customers, businesses and knowledge employee, we can take stakeholders from the three-way relationship, given the performance of knowledge employee definition: a knowledge employee performance is a process to create customer, enterprises and the value of its own staff to use their ability to achieve a specific role.

\subsection{The factors of Knowledge employee performance}

There are many factors affecting performance, it can be summarized in two parts, one is the personal factors, and the other part is the organizational factors [5].

1. Personal factors. It main including: (1) work motivation. Behavior is needed to generate incentives, job motivation affect job performance and motivation provide energy. In other words, motivation can lead to work hard, affect job performance to a certain extent. (2) knowledge and skills. Abilities, skills and knowledge are shown by physical and mental characteristics of employee. Abilities, skills are the most important for knowledge employee performance. (3) Level of effort. In general, the effort level of knowledge employee by many factors, including wages, promotion, recognition, recognition, achievement, honor and reward their work-related satisfaction etc. 
2. Organizational factors. It mainly includes: (1) Opportunities. Knowledge employee the make a point of individual growth, so as long as give them the opptunity to show talents and learn new knowledge, they will work hard to improve their performance. (2) Excitation. It is to meet the needs of employees to let them work hard to achieve organizational goals in the process. Incentives will affect a person's level of effort, and thus affect the individual job performance. (3) Work environment factors. Work environment can be a working atmosphere, it can be a office environments and light conditions etc. Improving environmental factors can affect personal ability and responsibility which can improve their job performance.

\section{The recommend to improve the performance of knowledge employee}

For factors affected knowledge employee performance, we propose the following countermeasures and Suggestions in order to improve their performance.

\subsection{Pay attention to the training of knowledge workers}

In the era of knowledge economy, talent competition will become more intense, human resource management is an important task to attract and retain talent. However, strong liquidity is contrary to this intention, knowledge employee focus more on individual growth rather than the needs of organizational goals. From that point, the enterprise should focus on investment in human capital firstly, and improve personnel training mechanism for knowledge workers to provide education and constantly improve their own skills which have a lifelong employability. Meanwhile, the enterprise not only to provide their employees with a reward commensurate with their contributions, but also to fully understand the employee's personal needs and wishes of career development, to provide a suitable development path of its requirements. Employees can clearly see their future development in the organization that can let them have the power to do their utmost to contribute their corporate strength, and set up a long-term cooperation and with the organization, and share weal and woe.

\subsection{Improve the organizational environment of knowledge employee}

Environmental factors has a very important impact on the performance of knowledge employee which is determined by the characteristics of knowledge employee, the enterprise should fully understand and grasp the basis of these characteristics to create conditions to reach the fullest potential actively. Knowledge employee generally wants a free and open system that can give themselves a sufficient support and trust. Liberal, independent work environment, good communication environment, fair, reasonable and competitive environment are the necessary prerequisites of the wisdom and knowledge staff capacity maximum release for knowledge employee.

\subsection{Pay attention to the incentive of knowledge employee.}

Tampoe's study found that knowledge workers have a significant impact on motivation factors include four aspects: job autonomy, business success, personal growth, money and wealth. Further empirical research identified four key motivators extent, as shown in Table 4.1. So money incentives should not be a major for knowledge workers, it should focus on their aachievements and developments. In addition, according to the theory of demand, different people have different needs at different stages, so enterprises should make the best incentive to develop solution to knowledge employee in different needs at different times. 
Table 4.1 The reaserch of knowledge staff incentive factors

\begin{tabular}{l|c|l}
\hline Incentive factors & Percentage & Preference \\
\hline personal growth & $33.74 \%$ & Accelerated growth \\
job autonomy & $50.51 \%$ & Work freely under certain condition \\
business success & $28.69 \%$ & Very high \\
money and wealth & $7.07 \%$ & Take wages and allowances as rewards of individual effort \\
\hline
\end{tabular}

\section{Summary}

Knowledge employee who use symbols and concepts, grasp and use of knowledge, or information workers who are highly autonomous, strong professional skills, a high level of demand and frequent mobility characteristics and so on, both individual and organizational factors can cause multiple effects to the performance of knowledge employee. Modern enterprises must be based on this reality, paid great attention to the training of knowledge employee, improve their organizational environment, and to take a variety of incentives to improve the performance level of knowledge employee.

\section{Reference}

[1]. Dong Nuxiao: Research of Knowledge-based Employee employee Management [J]. Economic Forum, 2007 (7): 78-79

[2]. Shi Yang. Characteristics and Incentive of Knowledge Employee [J].Lanzhou research, 2007 (12): 57-59

[3]. Chen Fei. Analysis and Management of Knowledge Employee Performance [J]. Technology and market, 2008 (10): 51-52

[4]. Liu Lihua. Research of Knowledge Employee Performance. [D]. Shandong University PhD thesis, 2006: 36-43

[5]. Le Guoling. Research of Knowledge Employee Knowledge Worker Performance Factors [D]. Hu NanUniversity Master Thesis, 2004: 27-37 